\title{
Analysis of Clinical Features of Patients with Depressive Disorder
}

\author{
Biljana Iliev \\ Clinical hospital, 2000 Stip, Republic of North Macedonia \\ E-mail:biliev@live.com \\ Irina Pavlovska \\ Institute of Epidemiology and Biostatistics with Medical Informatics, Medical Faculty, "Ss Cyril and \\ Methodius" \\ 1000 Skopje, Republic of North Macedonia \\ E-mail: irina.pavlovska@yahoo.com
}

\begin{abstract}
Depression is a mental disorder with a wide range of changes in mental functions, primarily affectivity, and is manifested by dysphoric mood and reductive changes in cognitive, conative and other psychic dynamisms, with the presence of psychosomatic disorders and suicidal thoughts. There is always a triad of symptoms involved: alteration of affectivity, anhedonia and low energy with fatigue, but in it's clinical picture there are other symptoms, such as guilt and powerlessness, obsession with " black thoughts " with loss of self - confidence, with hopelessness, loss of apetite, and weight loss with insomnia or hypersomnia present and more frequent thoughts of death because of worthlessness in life.Severe depressive disorder is not a homogenous mental disorder but a complex of clinical fenomena with subtypes, it is a series of special syndromes or clinical forms arranged continuously from lower to highest intensity of psychopathological clinical signs with or without psychoticisam to a high degree of risk for suicide. Severe depression also occurs as a comorbid illness with other mental illnesses and usually gets a chronic course.The Report of the World Health Organization from 2015 can be concluded that the Republic of Northern Macedonia has not submitted data on the prevalence and incidence of Severe Depressive Disorder. The presented data on a global level indicate that in the world and in the Balkan $7.5 \%$ of patients are treated in hospital.
\end{abstract}

Keywords: Severe depression, suicidal thoughts and attempts, comorbidities, hospitalizations.

DOI: $10.7176 / \mathrm{JHMN} / 92-01$

Publication date:August $31^{\text {st }} 2021$

\section{Introduction}

Depression is a common and debilitating disease yhat affects people from adolescence to old age and has a pronounced negative impact on the mental and phusical health, as well on the social and financial well - being of the individual and society.

The first episode of depression can occur at any age from childhood to old age, with an acute or slow onset and i'ts duration varies from a few weeks to several months.

Clinicians repeatedly point to the link between life events (especially those involving loss and separation, such as divorce and the death of a loved one ) and the onset of depression. Numerous studies using standardized instruments and diagnostic procedures confirm this finding. ( Jenaway 1997 ). Genetic predisposition to depression along with stressful life events is thought to influence the onset of depression, In the stydy of 2.164 female twins, Kendler and colleagues found that the incidence of depression increased significantly with the onset of stressful events, of which the so - called "Severe stressful events " - the death of loved one, physical assault, serious marital problems and divorce ( Kendler 1995 ). In the context of the adverse life events the importance of early life trauma as an etiological factor in the pathogenesis of depression by clinicians is particularly emphasized. Kessler and colleagues conducted that adverse childhood events were associated with early - onset depression ( Kessler 1996 ).

Burke suggests that poor parenting, marital disorder, modeling and enviromental factors all contribute to the development of psychiatric symptoms including depression in children ( Burkre 2003 ).

Kessler points out that people with depression have significant functional impairment in the home, work and social functioning ( Kessler 2003 ). This influence reflects on the individual, but also on society as whole in terms of the disabilty it brings with it. In 2001, neuropsychiatric conditions accounted for almost $30 \%$ of the total disability worldwide of which $11 \%$ were attributed to depression (Greden 2001 ). The consequences of depression for overall disability tend to increase. The cosequences of depression for overall disability tend to increase . In 1990 depression accounted for 3.7\% of the toatal disability and in 2000 for 4.4\%. ( Ustin 2004 ). Of particular concern is the prediction that such data are not considered to reflect the real threat that depression poses to society as a whole ( Wittchen 2011 ). This year according to the World Health Organization, depression is expected to come in the second place, right after ischemc heart disease in th terms of disability it causes. 
Depression also has serious economic and social consequences. The total cost of depression in Europe in 2010 was 113.4 billion euros. This icludes direct health care costs and non - medical costs ( around 60\% ), as well as costs associated with patient production losses ( aproximately $40 \%$ ).

\section{Purpose}

The aim of the research is to examine the clinical features of depressive episodes, as well as the role of the family in dealind wiyh this disease.

\section{Material and methods}

The research is an analytical cross - sectional study implemented in the three special psychiatric hospitals in the Northern Macedonia ( Psychiatric hospital - „, Skopje” - Skopje, Psychiatric hospital - „, Negorci” - Gevgelija, Psychiatric hospital - ,, Demir Hisar “- Demir Hisar in the period 2013 - 2017. The study covers all inpatients who meet the ICD 10 diagnostic criteria for diagnoses F32 and F33.

Data collection was done according to a previously designed non - standardized questionnaire ( compilation of questions used in similar studies ) with 9 closed - ended questions.

\section{Statistical analysis}

The data obtained during the research were statistically processed using SPSS software package, version 22.0 for Windows ( SPSS, Chicago, IL, USA ).

The analysis of the series with the attribute traits is done by determining the coeficient of relations, proportions and rates and they are presented as absolute and relative numbers. Numerical series are analyzed using the measures of central tendency ( average, median, minimum values, maximum values, interactive ranks ) as well as measures of dispersion ( standard deviation ). Non - parametric tests for two independent samples ( Mann Whitney - U test ) were used to test the significance of the difference between certain numerical parameters with incorrect frequency distribution. Risk factors are quantified using Odd ratio ( OR ) and confidence intervals ( CI ). The difference between the proportion was tested with the Percentage Difference test.

The hospital incidence of depressive disorders is calculated according to the number of hospitalized cases with depressive disorders per 1000 hospitalized for the respective year and hospital. Prevalence period is calculated according to the total number of hospitalized with depressive disorders per 1000 hospitalized for respective period and hospital. A significance level of $\mathrm{p}<0.05$ and 0.01 was used to determine the statistical significance.

\section{Results}

In the three specialized psychiatric hospitals in the Republic of Northern Macedonia ( Skopje, Negorci and Demir Hisar ) in the five - year period ( 2013 - 2017 ) were registered a total of 167 hospitalized patients with depressive disorders. The distribution according to the psychiatric hospital wher they are treated indicates that 28 ( $16.47 \%$ ) were treated in Skopje, 63 (37.72\% ) in Negorci and 76 ( $45.51 \%$ ) in Demir Hisar. For the five year period, most of the hospitalizeations of patients with depressive disorders were realized in 2016 in the hospitals in Skopje 11 ( 39.29\% ) and Negorci - 29 ( $46.03 \%$ ), and in Demir Hisar in $2014-21$ ( $27.63 \%$ ) patients ( Graph 1 ). The lowest number of hospitalizations with depressive disorders in the three hospitals was achieved in 2017 for a consequent $4(14.29 \%)$ vs. $3(4.76 \%)$ vs. ( $10.53 \%)$.

The main age at first hospitalization / pnset of depression is $30.25 \pm 12.3$ years, regardless of gender. In most patients of the whole sample, $127(76.05 \%$ ), the duration of the epizode is 1 year. In 5 ( five ) respondents ( $2.099 \%$ ) the duration of the epizode is 2 months, while in $12(7.19 \%)$ it is shorter than 2 months ( Table 2 ) with a statistically significant difference ( Chi- square test $=329.617^{* *}$, $\mathrm{df}=4 \mathrm{p}<0.01$ ). The analysis of the results indicates a significant association between the sex and the duration of the episode ( Fisher freeman Halton exact test $=0.063, \mathrm{p}=9548$ ).

The episodes were predicted by a stressful event in 198 ( $64.67 \%$ ) patients, with a statistically significant difference ( $\mathrm{Chi}-$ square test $=14.377^{* *}$, df $=1 \mathrm{p}<0.01$ ). No significant association was observed between gender and the existence of a stressful event ( Pearson Chi - square test $=1.9089 ; \mathrm{df}=1 ; \mathrm{p}=0.1671$ ).

The existence of domestic violence is confirmed by $110(65.89 \%)$ of the patients of which $59(73.75 \%)$ are women ( Table 2 ). The analysis shows that women with depressive disorder have 1.983 times [ OR=1.983 ( 1.03-3.821) 99\% CI], a greater experience of domestic violence compared to men with the same diagnosis, which is a statistically significant difference $\left(\chi^{2}=4,243 ; \mathrm{df}=1 ; \mathrm{p}=0,0394 *\right)$.

Suicidal ideation was present in $63(38.65 \%)$ of the patients, with a statistically ideation was present in 63 ( $38.65 \%$ ) of the patients, with a statistically significant difference ( Chi - square test $=8.399 * *, \mathrm{df}=1 \mathrm{p}=0.004$ ). Attempted suicide was registered in 50 (30.12\%) respondents, with a statistically significant difference ( Chi square test $\left.=26.241^{* *}, \mathrm{df}=1 \mathrm{p}<0.01\right)$ compared to those without suicidal thoughts and attempts.

Primary family care and support are available to a total of $84(50.30 \%)$ patients with depressive disorder, 
with no statistically significant difference ( $\mathrm{Chi}-$ square test $=0.006, \mathrm{df}=1, \mathrm{p}=0.938$ ) compared to those who do not receive support. The additional analysis indicates that men with depressive disorder have statistically significant higher support 2.464 times $[\mathrm{OR}=2.464(1.32-4.59) 99 \% \mathrm{CI}]=0.0042 *$ than the primary family care compared to women, $\left(\chi^{2}=8,194 ; \mathrm{df}=1 ; \mathrm{p}=0,0042 *\right)$ (Table 2$)$.

Table 2. Analysis of clinical features of patients with depressive disorder with gender specifics $(2013-2017)$

\begin{tabular}{|c|c|c|c|}
\hline \multirow[t]{2}{*}{ Parameter } & \multicolumn{2}{|c|}{ Gender } & \multirow[t]{2}{*}{ Total } \\
\hline & men & & \\
\hline \multicolumn{4}{|l|}{ Episode duration } \\
\hline Under 2 months & $6(6,90 \%)$ & $6(7,50 \%)$ & $12(7.19 \%)$ \\
\hline 2 months & $2(2,30 \%)$ & $3(3,75 \%)$ & $5(2.99 \%)$ \\
\hline 6 months & $5(5,75 \%)$ & $3(3,75 \%)$ & $8(4.79 \%)$ \\
\hline 6 months 1 year & $8(9,20 \%)$ & $7(8,75 \%)$ & $15(8.98 \%)$ \\
\hline$\geq 1$ year & $66(75,96 \%)$ & $61(76,25 \%)$ & $127(76.05 \%)$ \\
\hline \multicolumn{4}{|l|}{ Stresful } \\
\hline Yes & $52(59,77 \%)$ & $56(70,00 \%)$ & $108(64.67 \%)$ \\
\hline No & $35(40,23 \%)$ & $24(30,00 \%)$ & $59(35.33 \%)$ \\
\hline \multicolumn{4}{|c|}{ Thought for suicide } \\
\hline Yes & $33(38,82 \%)$ & $30(38,46 \%)$ & $63(38.65 \%)$ \\
\hline No & $52(61,18 \%)$ & $48(61,54 \%)$ & $100(61.35 \%)$ \\
\hline \multicolumn{4}{|c|}{ Attempt for suicide } \\
\hline Yes & $23(26,74 \%)$ & $27(33,75 \%)$ & $50(30.12 \%)$ \\
\hline No & $63(73,26 \%)$ & $53(66,25 \%)$ & $116(69.88 \%)$ \\
\hline \multicolumn{4}{|l|}{ Family violence } \\
\hline Yes & $51(58,62 \%)$ & $59(73,75 \%)$ & $110(65.87 \%)$ \\
\hline No & $36(41,38 \%)$ & $21(26,25 \%)$ & $57(34.13 \%)$ \\
\hline \multicolumn{4}{|c|}{ Family care and support } \\
\hline Yes & $53(60,92 \%)$ & $31(38,75 \%)$ & $84(50.30 \%)$ \\
\hline No & $34(39,08 \%)$ & $49(61,25 \%)$ & $83(49.70 \%)$ \\
\hline \multicolumn{4}{|c|}{ Mental comorbidities (F10, F11, F19) } \\
\hline Yes & $22(25,29 \%)$ & $9(11,25 \%)$ & $31(18,56 \%)$ \\
\hline No & $65(74,71 \%)$ & $71(88,75 \%)$ & $136(81,44 \%)$ \\
\hline \multicolumn{4}{|c|}{ Somatic comorbidities (hipertensio, cardiomiopatia) } \\
\hline Yes & $18(20,69 \%)$ & $14(17,50 \%)$ & $32(19,16 \%)$ \\
\hline No & $69(79,31 \%)$ & $66(82,50 \%)$ & $135(81,84 \%)$ \\
\hline
\end{tabular}

Somatic comorbidity (cardiovascular disease) was found in $31(19.16 \%)$ patients, with no significant presence $($ Chi-square test $=0.273, \mathrm{p}=0.6008)$ and no significant gender distribution differences.

Of the mental comorbidities, the most common are addiction diseases (alcoholism-F10 in 25, opiate addiction-F11 in 4 and dependence on various substances-F19 in 2), present in a total of 31 patients (18.56\%) without significant presence. On the other hand, there is a statistically significant difference in relation to this variable, with a higher prevalence in men (Pearson Chi-square test $=10.1636 ; \mathrm{df}=1 ; \mathrm{p}=0.0014 *$ ).

Of the entire sample of patients, $49(29.34 \%)$ have both hospital and outpatient treatment, while 118 $(70.66 \%)$ have only hospital treatment. The majority of patients $(23.95 \%)$ were hospitalized only once, while $18.56 \%$ were hospitalized five times. The average number of hospitalizations is $2.71 \pm 1.55$ with a minimum of 1 and a maximum of 5 hospitalizations. Half of the patients $(50 \%)$ had more than 2 hospitalizations for Median $\mathrm{IQR}=2(1-4)$. The average number of outpatient treatments is $2.85 \pm 1.87$ with a minimum of 1 and a maximum of 5 and $50 \%$ of patients with more than 2 outpatient treatments for Median IQR $=2(1-5)$. There is no significant difference between the two genders in terms of the number of hospitalizations, the number of outpatient treatments (Mann-Whitney U Test: $Z=-0.777 ; p=0.4371$ vs. $Z=-0.564 ; p=0.5726$ ) (Table 2) . 


\section{Discussion}

Out of the total number of hospitalized patients with depressive disorders in the three specialized psychiatric hospitals in Macedonia, for the five-year examination period, $87(52.10 \%)$ are men and $80(47.90 \%)$ are women with a sex ratio of 1.09: 1 in favor of men. This ratio contradicts the findings of numerous worldwide epidemiological studies which indicate a twice as high incidence of depression in women (Kessler 1993, Pedersen 2014). It is to be expected that such findings are in the context of the pronounced underdiagnosis of depression in our environment, especially among women.

Subdiagnosis of depression is a global problem, and its roots are in its lack of knowledge, non-standard forms of manifestation (with predominant somatic symptomatology) and especially the stigma that depression carries with it (Zung 1993, Simon 1999, Kirmayer 1993). The stigmatization of mental illnesses, including depression, is strongly expressed in our environment, more pronounced in the female population, and is an obstacle in the timely request for help in the occurrence of depression and receiving appropriate treatment. Globally, it is estimated that less than $50 \%$ of depressed patients receive treatment. In some countries, less than $30 \%$, and in some regions less than $10 \%$ of cases are treated (Marcus 2012). Resolving the stigma surrounding mental health can reduce resistance to seeking help early in the onset of depression and may improve the inadequate degree of diagnosis and treatment of people with depressive symptoms (Bagayogo 2013).

Significantly higher frequency of hospitalization lasting more than one year for the entire sample of respondents in this study, which again leads to the conclusion that in our environment depressed patients present for treatment only in a severe clinical picture that requires long-term hospital treatment.

Regarding the analysis of the existence of a stressful event (so-called severe stress - loss of a loved one, divorce) before the onset of the depressive episode, it has a significant frequency for the whole group of respondents. This finding is consistent with clinical experience and findings from epidemiological studies on the association of adverse life events, particularly those involving loss and the occurrence of depression (Jenaway 1997; Kendler 1995).

In this research, domestic violence has a significantly higher frequency for the whole group of respondents, with 1,983 times $[\mathrm{OR}=1,983(1.03-3,821) 99 \% \mathrm{CI}]$ higher frequency in women $(\chi 2=4,243 ; \mathrm{df}=1 ; \mathrm{p}=0,0394$ *). Domestic violence as its sub-form contains child abuse which as an early trauma is strongly associated with later onset of depression and it is much more common in all epidemiological studies in the female population (Bifulco 1998, Pedersen 2014).

Primary family care and support is 2,464 times $[\mathrm{OR}=2,464(1.32-4.59) 99 \% \mathrm{CI}]$ higher in men than in women. This finding can be interpreted by the traditionally greater commitment of women in the overall care of the family and its members in health and disease in our environment.

Thought of suicide was found in $38.65 \%$, and attempted suicide in $30.12 \%$ of the entire group of respondents without significant gender difference. This finding correlates with a number of studies that confirm a high incidence of suicidal ideation in patients with depression (Gensichen 2010). There is no doubt that suicidal ideation and suicide attempts are the greatest danger in depression and are a major health problem and leading cause of death worldwide (Desseilles 2012).

In terms of comorbidity, somatic comorbidity (cardiovascular disease) was found in $19.16 \%$ of patients without significant gender association, and mental comorbidity (addiction disease) in 18.56\% again without significant gender association. This finding is consistent with the most common somatic comorbid conditions (cardiovascular disease) and psychiatric conditions (addictive disease) (Musselman 1998, Stoner 1998, Evans 1999, Lyness 2006, Merikangas 1990, Gros 2013, Darke 1997).

Out of the entire sample of patients, $49(29.34 \%)$ have both hospital and outpatient treatment, while 118 $(70.66 \%)$ have only hospital treatment. The majority of patients $(23.95 \%)$ were hospitalized only once, while $18.56 \%$ were hospitalized five times. The average number of outpatient treatments is $2.85 \pm 1.87$ with a minimum of 1 and a maximum of 5 and $50 \%$ of patients with more than 2 outpatient treatments. Significantly higher frequency of hospitalizations lasting more than a year with the simultaneous low representation of outpatient examinations indicate the inadequate treatment and the absence of pre- and post-hospital care for depressed patients in our environment.

Improving the understanding of depression in our environment would help in the necessary efforts to reduce the stigma surrounding mental health that contributes to the problems we face in treating depression, especially the late arrival of patients for treatment, as well as developing a comprehensive early diagnosis system. , treatment and monitoring of this disorder.

\section{Conclusion}

The ratio of both sexes in hospitalized patients with depression (1.09: 1 in favor of men) in this study differs significantly from studies in the world, where the incidence of depression in women is twice as high. This can be interpreted by the pronounced stigma that depression brings primarily to the female population that prevents them from calling and asking for help. 
Male respondents with depression are significantly more likely to receive support from the primary family compared to women, which is in line with the traditionally greater commitment of women in the overall care of the family and its members in health and disease in our environment.

Severe stressful events and domestic violence are significantly more frequent precursors of the depressive episode for the whole group of respondents.

Cardiovascular and addictive diseases were the most common comorbidities in subjects without gender differences.

The first onset of depression (at 30.25 years), as opposed to the average age of respondents in the whole group (50.59 years), as well as the significantly higher frequency of hospitalizations lasting more than one year again indicates the late start of treatment of depression which most often is taken in pronounced clinical pictures with a high frequency of suicidal ideation and attempts that require long-term hospital treatment.

Improving the understanding of depression in our environment would help in the necessary efforts to reduce the stigma surrounding mental health that contributes to the problems we face in treating depression, especially the late arrival of patients for treatment, as well as developing a comprehensive early diagnosis system. , treatment and monitoring of this disorder.

\section{References}

1. Bagayogo IP, Interian A, Escobar JI. Transcultural aspects of somatic symptoms in the context of depressive disorders. Adv Psychosom Med 2013; 33:64-74.

2. Ben-Zeev, D., Young, M. A., \& Depp, C. A. (2012). Realtime predictors of suicidal ideation: Mobile assessment of hospitalized depressed patients. Psychiatry Research, 197(1-2), 55-59.

3. Bifulco A, Brown GW, Moran P, et al. Predicting depression in women: the role of past and present vulnerability. Psychol Med 1998;28(1):39-50.

4. Burke L: The impact of maternal depression on familial relationships. Int Rev Psychiatry 2003; 15:243-55.

5. Burt VK, Stein K: Epidemiology of depression throughout the female life cycle. J Clin Psychiatry 2002; 63(Suppl 7):9-15.

6. Darke S., Ross J., Polydrug dependence and psychiatric comorbidity among heroin injectors, Drug and Alcohol Dependence, Volume 48, Issue 2, 1997, Pages 135-141

7. DiMatteoM. R, H. S. Lepper, and T. W. Croghan, "Depression is a risk factor for noncompliance with medical treatment metaanalysis of the effects of anxiety and depression on patient adherence," Archives of Internal Medicine, vol. 160, no. 14, pp. 2101-2107, 2000.

8. Gater R, Tansella M, Korten A, Tiemens BG, Mavreas VG, Olatawura MO. Sex differences in the prevalence and detection of depressive and anxiety disorders in general health care settings: report from the World Health Organization Collaborative Study on Psychological Problems in General Health Care. Arch Gen Psychiatry 1998; 55:405-13.

9. Gensichen, J., Teising, A., König, J., Gerlach, F. M., \& Petersen, J. J. (2010). Predictors of suicidal ideation in depressive primary care patients. Journal of Affective Disorders, 125(1-3), 124-127.

10. Greden JF: The burden of disease for treatment-resistant depression. J Clin Psychiatry 2001; 62(Suppl 16):26-31.

11. Heim C, Newport DJ, Heit S, et al. Pituitary-adrenal and autonomic responses to stress in women after sexual and physical abuse in childhood. JAMA 2000;284(5):592-597.

12. Katon W, Rutter C, Ludman EJ, Von Korff M, Lin E, Simon G, Bush T, Walker E, Unützer J : A randomized trial of relapse prevention of depression in primary care. Arch Gen Psychiatry 2001; 58:241-7.

13. Kessler RC, Gillis-Light J, Magee WJ, et al. Childhood adversity and adult psychopathology. In: Gotlib IH, Weaton B, eds. Trajectories andturning points: stress andadversity over the life course. New York: Cambridge University Press, 1996.

14. Kessler RC, McGonagle KA, Zhao S, Nelson CB, Hughes M, Eshleman S, Wittchen HU, Kendler KS. Lifetime and 12-month prevalence of DSM-III-R psychiatric disorders in the United States. Results from the National Comorbidity Survey. Arch Gen Psychiatry 1994; 51:8-19

15. Kirmayer LJ, Robbins JM, Dworkind M, Yaffe MJ: Somatization and the recognition of depression and anxiety in primary care. Am J Psychiatry 1993; 150:734-41.

16. Limosin F, Loze JY, Zylberman-Bouhassira M, Schmidt ME, Perrin E, Rouillon F: The course of depressive illness in general practice. Can J Psychiatry 2004; 49:119-23.

17. Lyness JM,Niculescu A,Tu X,Reynolds CF 3rd,Caine ED, The relationship of medical comorbidity and depression in older, primary care patients. Psychosomatics. 2006 Sep-Oct; [PubMed PMID: 16959933]

18. Marcus M, TaghiYasamy M, van Ommeren M, Chisholm D, Saxena S. DEPRESSION - A Global Public Health Concern 2012 WHO

19. McCauley J, Kern DE, Kolodner K, et al. Clinical characteristics of women with a history of childhood abuse: unhealed wounds. JAMA 1997;277(17):1362-1368. 
20. MerikangasK., SheaGelernter C., Comorbidity for Alcoholism and Depression, Psychiatric Clinics of North America, Volume 13, Issue 4, December 1990, Pages 613-632

21. Murray C. J. L. and A. D. Lopez, “Alternative projections of mortality and disability by cause 1990-2020. Global Burden of Disease Study,” Lancet, vol. 349, no. 9064, pp. 1498-1504, 1997.

22. Musselman DL, Evans DL, Nemeroff CB. The relationship of depression to cardiovascular disease: epidemiology, biology, and treatment. Arch Gen Psychiatry 1998;55(7):580-592

23. Pedersen CB,Mors O,Bertelsen A,Waltoft BL,Agerbo E,McGrath JJ,Mortensen PB,Eaton WW, A comprehensive nationwide study of the incidence rate and lifetime risk for treated mental disorders. JAMA psychiatry. 2014 May; [PubMed PMID: 24806211]

24. Simon GE, VonKorff M, Piccinelli M, Fullerton C, Ormel J. An international study of the relation between somatic symptoms and depression. N Engl J Med 1999; 341:1329- 1335

25. Thapar A, Collishaw S, Pine DS, ThaparAK, Depression in adolescence. Lancet 2012; 379(9820):10561067.

26. Ustün TB, Ayuso-Mateos JL, Chatterji S, Mathers C, Murray CJ: Global burden of depressive disorders in the year 2000. Br J Psychiatry 2004; 184:386-92.

27. WHO: International statistical classification of diseases (ICD-10), 2010.

28. Wittchen HU, Jacobi F, Rehm J, Gustavsson A, Svensson M, Jönsson B, Olesen J, Allgulander C, Alonso J, Faravelli C, Fratiglioni L, Jennum P, LiebR, Maercker A, van Os J, Preisig M, Salvador-Carulla L, Simon $\mathrm{R}$, Steinhausen HC. The size and burden of mental disorders and other disorders of the brain in Europe 2010. EurNeuropsychopharmacol 2011; 21:655-79. 